\title{
Towards Ethically Responsive Online Education: Variables and Strategies from Educators' Perspective
}

\author{
Tahani I. Aldosemani ${ }^{1}$ \\ ${ }^{1}$ College of Education, Prince Sattam bin Abdulaziz University, Alkharj, Saudi Arabia \\ Correspondence: Tahani I. Aldosemani, College of Education, Prince Sattam bin Abdulaziz University, Alkharj, \\ Saudi Arabia. E-mail: t.aldosemani@psau.edu.sa
}

Received: September 30, 2019

Accepted: November 3, 2019 Online Published: January 6, 2020

doi:10.5539/jel.v9n1p79

URL: https://doi.org/10.5539/jel.v9n1p79

\begin{abstract}
The main purpose of this study is to quantitatively identify the most recurrent ethical challenges instructors usually encounter in their online teaching and the most effective strategies to solve and avoid these challenges. Among the faculty members, 52\% stated that they encountered certain ethical challenges in their teaching. Although ANOVA tests showed that there is no significant difference between instructors with different academic degrees and different teaching experiences. This shows that that the probability of these challenges could occur in online learning environments regardless instructors' academic degree or online teaching experiences.
\end{abstract}

Keywords: ethical challenges, online education, online instructors, effective strategies

\section{Introduction}

Ethics are an integral part of the teaching profession. The advent of online education brought further demands for educators and students to maintain ethical principles in their profession and to act with integrity within these online environments. Online learning has given countless learning, educational and academic opportunities for many students all across the globe. It has amplified the learning experience and facilitated the learning process. Anderson and Simpson (2007) stated that, "online teaching environments amplify the ethical issues faced by instructors and students. Online sites support complex discourses and multiple relationships; they cross physical, cultural, and linguistic boundaries" (p. 129). Educators through online courses have to build effective ethical environments for learners and encourage creating ethical network among learners themselves. On the contrary, ethical issues arise with the new generation's type of learning. Schultz (2005) defined ethics as 'what people should do' relating to morality, value and justice. Online learning ethical concerns vary from improper citing to academic fraud Bušíková and Melicheríková (2013). Reynolds (2007) defined the professional codes of ethics as "the principles and core values essential to the work of a particular occupational group" (p. 33). Although these principles and values are important to the work of groups, few professional ethics and ethical challenges of online courses are grounded in empirical research (Mabry \& O’Driscoll, 2003, cited in Lin, 2007). Furthermore, the lack of empirical studies in the area of ethics in instructional technology has obviously become a concern (Coleman, 2012; Lin, 2007). Yeaman (2004) considered the area of professional ethics in using technology in education a relatively neglected topic of research. This paper will discuss the ethical issues involved with e-Learning, and present strategies and recommendations that may be implemented in academic premises (virtually and physically) to create a safe academic environment for online learners.

Zembylas and Vrasidas (2005) considered that one of the most critical challenges in online education is ethical in nature. They pointed out that both instructors and learners have ethical responsibility towards the 'other's' diverse and complex identities. They stated "through online education, teachers and students become virtually implicated in ethical interactions in which they have to consider how they should respond to each other" (p. 77). They argued that an ethical online pedagogy requires paying attention to the ways in which interactions across different individuals promote relationality, criticality, and responsibility. Brey (2006) discussed the importance of identifying the unethical behaviors by students and staff and highlighted the importance of providing suitable coping strategies to solve these challenges. He also discussed important ethical issues such as, the capability of these online educational settings to stimulate or hinder learners' academic freedom, promote diversity and, foster equality and equity for students. 
Ethical issues in E-learning occur frequently and it have been argued that e-Learning limits the student from reaching his or her full potential. As Khoury (2011) stated the lack of control causes low motivation for the students, which leads them to not take their tasks seriously and properly. Another common issue is the academic fraud in online environments. As Nagi (2006) mentioned, it takes less effort to cheat in online environments as opposed to face-to-face learning. Pavela (2009) conducted a survey, which revealed that $59 \%$ of students have committed some sort of academic fraud. Kročitý (2013) also conducted a study on the students of Slovakia, which exposed that the most common sources of information are reached through teachers. Hence that face-to-face contact with teachers is solemnly limited, this may lead to students 'accidentally' plagiarizing. Bušíková and Melicheríková (2013) discussed recurrent ethical issues that included improper citing, asking someone else to sit for them during exams, browsing the internet during an online test, and paying someone else to write and participate on behalf of the registered student. Therefore, raising the level of honesty and mutual trust is vital in all academic environments, which will encourage students to reach their full potentials and motivate each other (Bušíková \& Melicheríková, 2013).

The issues of equality, diversity, privacy, and learners' freedom are the most ethical concerns discussed in the literature and there are blurred lines between students and instructors' ethical rights in online educational contexts. Lin (2007) identified and discussed three ethical issues in the literature that he concluded need further exploration. These issues included (1) The use of copyright protected materials in distance education, (2) protecting learners' privacy and their individual rights, (3) helping individuals with disabilities in getting access to online learning opportunities, (4) providing equal access to diverse groups, (5) conflicts of interest of the learners' needs and goals, and (6) professionalism. Lin (2007) underscored five coping strategies proposed by professional technologists in design and training situations through extensive experiential interviews. These strategies were (1) team communication, (2) law and policies, (3) management consultation, (4) professional integrity, and (5) technical solutions.

Anderson and Simpson (2007) emphasized the ethical issues of learners' privacy and diversity. They stated that with the growing embrace of online education, these issues are seldom discussed. They argued that those who are traditionally disadvantaged groups in educational systems are having similar difficulties in online learning contexts. They recommended that online education has to eliminate possible ethical barriers to ensure that its advantages reach everyone. They maintained that online courses aiming for cross-cultural participation must be designed and facilitated to improve culturally inclusive learning. They raised certain issues that need to be discussed from instructors' perspectives such as, the issues of to what extent educators recognize the impact of power in online courses? and how much are they prepared or able to work through an ethical responsibility to maximize learning opportunities for all students in the class? Anderson and Simpson (2007) concluded that online educational contexts create a range of ethical issues that need to be discussed through exploring both instructors and students' perspectives. They concluded by raising a number of critical questions related to professional ethics:

Is universal access to education an imperative for online educators? Should you require participation? How responsible are educators for changes beyond the bounds of the course? (To what extent) should you use data, automatically collected and archived, about student engagement? Should you ask for permission to use it? What threats to identity and confidentiality exist in online courses, and what threats are posed by use of anonymity? (p. 136)

Wang and Hefferman (2010) pointed that "much of the existing literature that deals with ethical issues in the e-learning classroom overwhelmingly focuses on learners' online privacy, and the observations are usually only from the viewpoint of a third party, that is, as a spectator or an external evaluator" (p. 798). Given this fact, this study strives to examine if certain variables could have an effect on instructors' facing ethical issues mentioned in the literature such as their academic degree and teaching experience. The issues of power, copyrights and learners' privacy, inequality and diversity, and freedom are investigated through examining the impact of academic degree and teaching experience in the possibility of having such issues in their online teaching. Another purpose of this study is to identify a number of coping strategies to these ethical challenges from instructors' perspective as they are the facilitator of online education.

The exploration of the impact of instructors' academic degree and teaching experience in facing ethical considerations will support selecting the most appropriate and effective plans of preparing and training of online instructors and will eventually support the quality of design, delivery, and application of online courses. Further, the solutions that the instructors discussed as coping strategies will support the literature with practical solutions from instructors' perspectives. 


\section{Method}

The sampling frame for this study comprised male instructors with doctoral, master, and bachelor degrees in three universities in Saudi Arabia where online method of instruction was integrated for three to four years. Participants' ages ranged from 24 to 50 years old. The participants varied in their experience in online teaching from 1 to 6 years. They teach 1 to 4 classes every semester. Out of the 80 instructors received the survey by email, 34 instructors responded respectively with a response rate $42.5 \%$.

The participants completed a survey assessing their opinions of ethical challenges they usually encounter in online instructional environments and the most effective solutions or strategies to maintain ethical online environment. The survey statements were developed by reviewing the current literature of the most recurrent ethical challenges in online instructional environment and best coping strategies. The survey consisted of two sections, section 1 of the survey consisted of 12 ethical challenges in online courses on a Likert-scale measuring the frequency of the occurrences of such ethical challenges from unlikely to most likely with four intermediate scale points available between the labels to show how likely the respondent to encounter these challenges. Section 2 of the survey consisted of eight strategies on Likert-type items from strongly agree to strongly disagree with four intermediate scale points available between the labels to show how much the respondent agrees or disagrees with each statement. Both sections of the survey were followed by open-ended questions to receive more feedback from the instructors if they have additional comments and to include further challenges or solutions not mentioned in the survey. Following data collection, reliability analyses were performed on the instrument. The internal reliability coefficient for the instrument was high $(\alpha=0.89)$. Participants responded anonymously to the survey online, which took approximately 20 minutes to complete.

\section{Results}

The participants were 34 instructors in three different universities. Among the participants, 24 were with Doctoral degrees (70.6\%); 8 with Masters' (23.5\%), and 2 with Bachelor degrees (5.9\%) (See Figure 1). Among the participants, 18 instructors $(52.9 \%)$ reported that that they have one to two years in online teaching, 11 instructors (32.4\%) with two to three years, 3 instructors (8.8\%) with three to four years, and 2 instructors (5.9\%) with four to five years.

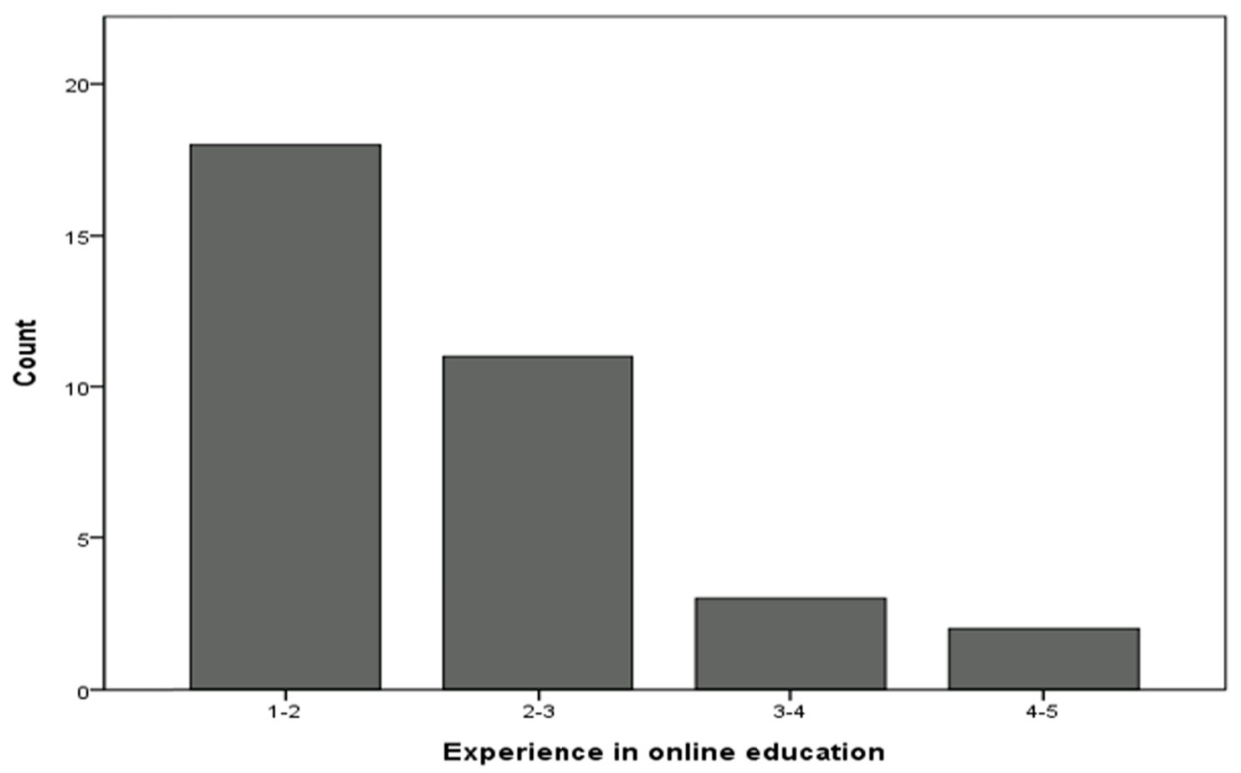

Figure 1. The number of professors with each type of academic degree in the sample

Among the participants, 34 instructors (17. 50\%) reported that they usually teach one class every semester, 10 of them $(29.4 \%)$ teach two classes every semester, $7,(20.6 \%)$ teach three classes every semester. Among the 34 instructors, 2 (5.9\%), reported that their institutions integrated online education one to two years ago, 15 (44.1\%) for two to three years, 17 (50\%) for three to four years (see Table 1 for means and standard deviations). 
Table 1. Descriptive Statistics of Participants Teaching Backgrounds

\begin{tabular}{lll}
\hline Group $^{a}$ & $M$ & $S D$ \\
\hline Number of online courses & 1.71 & .799 \\
Experience in online education & 1.68 & .878 \\
Integration of online ED & 2.44 & .613 \\
\hline
\end{tabular}

Note. $a_{n}=34$.

After one month of data collection, 34 surveys were collected and analyzed using SPSS version 18 . The means and standard deviations of instructors' responses according to their experience in online education were computed to determine the probability of instructors' encounter of such ethical challenges according to their teaching experience (see Table 2). In addition, a one-way analysis of variance with Scheffe post hoc analysis was used to determine if any significant differences were present between the groups with different online teaching experiences. The analysis showed that there were no significant differences among the groups' years of experience in online teaching and protecting students' privacy $(F(3.30)=1.701, \mathrm{p}>.05)$; providing students with equal access opportunities to the course $(F(3.30)=1.678$, $\mathrm{p}>.05)$; giving sufficient instructions to learners with disabilities to access the course $(F(3.30)=1.609, \mathrm{p}>.05)$; ( see Table 2$)$.

Other than the teaching experience, there is another factor that could make a difference in encountering and dealing with the aforementioned ethical challenges which is the academic degree that the online instructor has. The means and standard deviations of instructors' responses according to their academic degree was computed to determine the probability of instructors' encounter of such ethical challenges according to their academic degree (see Table 3). A one-way analysis of variance with Scheffe post hoc analysis was used to determine if any significant differences were present between the groups with different academic degrees. The analysis showed that there were no significant differences among the three groups' and having the challenge protecting students' privacy $(F(2.31)=3.266, \mathrm{p}>.05)$; providing students with equal access opportunities to the course $(F(2.31)$ $=1.112, \mathrm{p}>.05)$; giving sufficient instructions to learners' with disabilities to access the course $(F(3.30)=.331$ $\mathrm{p}>.05)$; consider diverse students perspectives $(F(2.31)=1.075, \mathrm{p}>.05)$; distribute course tasks equally among class members $(F(2.31)=1.732, \mathrm{p}>.05)$. However, the statistical analysis showed a significant difference among the groups regarding the challenge of maintaining students' confidential information $(F(3.31)=5.019, \mathrm{p}<.05)$. Post hoc Scheffe test showed that instructors with doctoral degrees differ significantly from each of the other two groups, instructors with bachelor and masters', but the difference between the bachelor and doctoral was not statistically significant. The size of the effect is quite small: doctoral instructors predicts only $(\eta 2=2.445)$ in the variability for the variable protecting students' confidential information (see Table 3).

Another purpose of this study is to define the most effective strategies to solve possible ethical problems in online education. The instructors agreed with most of the proposed solutions. With encouraging students to maintain ethical behavior (79.4\%) of participants strongly agreed with the strategy, with storing students' information safely $(70.6 \%)$ strongly agreed. With guiding the students in using copyright protected materials, (61\%) strongly agreed, with including and explaining dishonesty codes, (52.9\%) strongly agreed, with working with other faculty members in solving ethical problems, $(66.7 \%)$ strongly agreed, with following the institution guidelines $(76.5 \%)$ strongly agreed, with following educational policies in protecting students' privacy, $(76.5 \%)$ strongly agreed, with using common sense in solving ethical problems, (50\%) strongly agreed.

The open-ended question Are there any ethical challenges you experienced and not mentioned in this survey? generated other ethical challenges which instructors encountered. One instructor indicated that it is important to know the culture of the student. He mentioned that they have students from over 60 countries who came from different academic and cultural backgrounds. He noted that instructors have to clearly identify and explain ethical behaviors of online learning environments because what might appear or seem as a common sense to instructors might not appear as common sense to these diverse students.

Moreover, one instructor explained that they usually encounter certain types of plagiarism with what he called with 'good intentions' simply because this is what they used to do without proper previous ethical guidance. For example, students giving answers to an assignment with the intentions of helping others. Related to this another type of plagiarism, which one instructor identified as self-plagiarism when students usually do not know that it is a type of misconduct like submitting the same assignment or research for different courses without any changes. Other unethical practices that instructors discuss is the disclosure of information about students, changing some components or requirements of the course to satisfy the needs of some students without considering others' needs, ignoring some questions during the live or threaded discussion or paying more attention to active students 
and ignoring others.

The open-ended question about the most effective strategies to maintain ethical environment generated a number of effective strategies. One of the respondents suggested assigning extra credits for students who participate in live sessions in the Learning Management System such as, Elluminate to share their ideas or concerns about the course in general and provide their feedback to improve the quality of the course. Another instructor suggested giving students more space to express their personal opinions and respect these opinions by allowing students to discuss the validity or reliability of any idea mentioned in the course or the curriculum. He added that instructors can exploit the opportunity during the class to connect and discuss any ideas students come across to stimulate discussion around ethical practices or challenges in educational environments. In addition, he recommended discussing and explaining the common and different types of ethical practices in the online environments prior to the course with the possible solutions to solve these challenges.

\section{Discussion}

This study aimed at quantitatively measuring the ethical challenges instructors usually encounter in their online teaching and the most effective strategies to solve and avoid these challenges. Among the faculty members, $52 \%$ reported that they encountered these ethical challenges in their teaching. This finding is consistent with previous research and supports several ethical issues that have been discussed in the literature. Although ANOVA tests showed that there is no significant difference between instructors with different academic degrees and different teaching experiences except with one ethical issue, this is highly indicative that the probability of these challenges occurrence is not related to the instructors' academic degree or his or her online teaching experiences, instead they could occur with any instructor regardless of these factors. In addition, there could be other factors that could cause these ethical issues to happen and consequently affect the quality of delivering and managing online courses.

Another purpose of this study was to define the most effective strategies that could prevent or solve such ethical issues. All instructors agreed with the proposed solutions and strategies to avoid unethical issues and practices in the online environment. In addition, they provided more ideas and recommendations in how to maintain ethical atmosphere throughout the online course. One of the most effective strategies instructors can apply to overcome ethical dilemma in online courses is by creating a list of code of conduct. Further, Yonkers (2005) recommended encouraging students to write their own code of conduct. By engaging students in the research, assessment, and discussion of ethics, they will take ownership of the codes and the consequences of violating them (Anakwe \& Thomas-Haysbert, 2009). Regardless academic degree and teaching experience, faculty need reliable methods to prepare effective and flexible policy regarding ethics in educational settings (Grimes, 2004). However, it is more needed in online education due to the challenge of lack of direct face-to-face communication between instructor and students (Coleman, 2012). Coleman (2012) suggested engaging students in evaluating online learning processes through workshops and self-organizing groups. Further, the same pedagogical approach that teach ethics in the traditional classroom can be applied in online teaching that may include an introduction to ethics and examples of acceptable and unacceptable ethical behaviors "using what-if scenarios" (p. 3). He added that faculty and administrators should guide, articulate, and communicate standards and consequences of the violation of code of ethics (McCabe \& Pavela, 2004). Some resolutions are discussed by Bušíková and Melicheríková (2013) to enhance the ethical e-Learning environment such as implementing, academic plagiarism checker technology and focusing on plagiarism prevention by intensifying student teacher forums.

This study aimed at filling a gap in the literature where the issue is either discussed from theoretical angle or from third parties' perspectives such as, instructional designers. Moreover, this study explored the issue quantitatively and this approach enabled further perspectives and generated various viewpoints which ultimately enriched the findings of this study. Further studies could include even more voices such as, including the students whose perceptions embody an important factor in the success of the whole online educational process. Students' responses could be utilized to compare and contrast them with the instructors' perspectives to examine the differences and raise instructors' awareness of students needs regarding ethics. Moreover, future studies could include the institution administrators who have indirect impact on the online educational environment and could participate in defining the best organizational procedures that could improve the quality of online education.

Several limitations of this study are evident. Ethical challenges were obtained through self- reports therefore they are subject to personal bias. In addition, the nature of the study is questioning the occurrence of certain ethical and unethical practices in the online environment. Thus, with this type of questions, participants might not feel comfortable or reserve reporting the true issue as they might feel this will have negative consequences on their 
positions as instructors. Finally, including larger sample of instructors will enrich the data and the findings of this study.

\section{References}

Anakwe, B., \& Thomas-Haysbert, C. (2009). The impact of a code of conduct on student cheating. Consortium Journal of Hospitality \& Tourism, 13(2), 15-32.

Anderson, B., \& Simpson, M. (2007). Ethical issues in online education. Open Learning: The Journal of Open and Distance Learning, 22(2), 129-138. https://doi.org/10.1080/02680510701306673

Brey, P. (2006) Social and ethical dimensions of computer-mediated education. Journal of Information, Communication and Ethics in Society, 4(2), 91-101. https://doi.org/10.1108/14779960680000284

Buff, C. L., \& Yonkers, V. (2005). Using student generated codes of conduct in the classroom to reinforce business ethics education. Journal of Business Ethics, 61, 101-110. https://doi.org/10.1007/s10551-005-0273-6

Bušíková, A., \& Melicheríková, Z, (2013, July 22-26). Eyhics in e-learning. In M. B. Nunes \& M. McPheson (Eds.), Proceedings of the IADIS international conference on e-learning (pp. 435-438). Prague.

Coleman, P. D. (2012). Ethics, Online Learning and Stakeholder Responsibility for a Code of Conduct in Higher Education. Kentucky Journal of Excellence in College Teaching and Learning, 9. Retrieved from https://encompass.eku.edu/kjectl/vol9/iss1/3

Grimes, P. (2004). Dishonesty in academics and business: A cross-cultural evaluation of student attitudes. Journal of Business Ethics, 49(6), 273-291. https://doi.org/10.1023/B:BUSI.0000017969.29461.30

Khoury, H. (2011). E-Learning: Justifications and Obstacles. iJET, 53-56

Kročitý, P. (2013). Applying Principles of Scholastic Honesty in Higher Education: Are We on the Right Track?

Lin, H. (2007). The ethics of instructional technology: Issues and coping strategies experienced by professional technologists in design and training situations in higher education. Educational Technology Research and Development, 55(5), 411-437. https://doi.org/10.1007/s11423-006-9029-y

McCabe, D., \& Pavela, G. (2004). Ten (Updated) Principles of Academic Integrity: How Faculty Can Foster Student Honesty. Change: The Magazine of Higher Learning, 36(3), 10-15. https://doi.org/10.1080/00091380409605574

Nagi, K. (2006). Solving ethical issues in eLearning. International Journal of the Computer (Special issue: the Internet and Management), 14(SP1), 71-76.

Pavela, G. (1993). Academic integrity and cultural diversity (pp. 95-96). Syntax Weekly Report, May 24 (93.99). Proceedings from international conference Managing Intangibles.

Reynolds, G. (2007) Ethics in Information Technology (2nd ed.). Boston, MA: Thompson Course Technology.

Schultz, R. A. (2005). Contemporary Issues in Ethics and Information Technology. Hershey, PA, USA: IRM Press.

Wang, S., \& Heffernan, N. (2010). Ethical issues in Computer-Assisted Language Learning: Perceptions of teachers and learners. British Journal of Educational Technology, 41(5), 796-813. https://doi.org/10.1111/j.1467-8535.2009.00983.x

Yeaman, A. R. (2004). Professional ethics: The misuse of technology. Tech Trends, 48(5), 16-18. https://doi.org/10.1007/BF02763524

Zembylas, M., \& Vrasidas, C. (2005). Levinas and the 'inter-face': The ethical challenge of online education. Educational Theory, 55(1), 61-78. https://doi.org/10.1111/j.1741-5446.2005.0005a.x 


\section{Appendix A}

Table 2. One-way ANOVA for ethical challenges among different teaching experiences

\begin{tabular}{|c|c|c|c|c|c|}
\hline Source & Sum of Squares & $d f$ & Mean Square & $F$ & $P$ \\
\hline \multicolumn{6}{|c|}{ PROTECT PRIVACY } \\
\hline Between Groups & 14.314 & 3 & 4.771 & 1.701 & .188 \\
\hline Within Groups & 84.157 & 30 & 2.805 & & \\
\hline Total & 98.471 & 33 & & & \\
\hline \multicolumn{6}{|c|}{ PROVIDE EQUAL ACCESS } \\
\hline Between Groups & 12.988 & 3 & 4.329 & 1.678 & .193 \\
\hline Within Groups & 77.394 & 30 & 2.580 & & \\
\hline Total & 90.382 & 33 & & & \\
\hline \multicolumn{6}{|c|}{ PROVIDE LD EQUAL ACCESS } \\
\hline Between Groups & 7.561 & 3 & 2.520 & 1.609 & .209 \\
\hline Within Groups & 45.409 & 30 & 1.566 & & \\
\hline Total & 52. 970 & 33 & & & \\
\hline \multicolumn{6}{|c|}{ CONSIDER DIVERSITY } \\
\hline Between Groups & 6.224 & 3 & 2.075 & 1.402 & .261 \\
\hline Within Groups & 44.394 & 30 & 1.480 & & \\
\hline Total & 50.618 & 33 & & & \\
\hline \multicolumn{6}{|c|}{ PROTECT CONFIDENTIAL INFO } \\
\hline Between Groups & 10.105 & 2 & 9.525 & 5.019 & .013 \\
\hline Within Groups & 67.778 & 30 & 2.259 & & \\
\hline Total & 77.883 & 32 & & & \\
\hline \multicolumn{6}{|c|}{ DISTRIBUTE TASKS EQUALLY } \\
\hline Between Groups & 9.488 & 3 & 3.163 & 1.549 & .222 \\
\hline Within Groups & 61.247 & 31 & 2.042 & & \\
\hline Total & 70.735 & & & & \\
\hline \multicolumn{6}{|c|}{ ENCOURAGE INDEPENDENCY } \\
\hline Between Groups & 8.214 & 3 & 2.738 & 1.259 & .306 \\
\hline Within Groups & 65.227 & 30 & 2.174 & & \\
\hline Total & 73.441 & 33 & & & \\
\hline \multicolumn{6}{|c|}{ AVOID POWER RELATIONS } \\
\hline Between Groups & 14.276 & 3 & 4.759 & 2.148 & .115 \\
\hline Within Groups & 80.208 & 30 & 2.215 & & \\
\hline Total & 94.484 & 33 & & & \\
\hline \multicolumn{6}{|c|}{ SURVEILLANCE OF INTERACTION } \\
\hline Between Groups & 1.315 & 3 & .438 & .216 & .884 \\
\hline Within Groups & 60.803 & 30 & 2.027 & & \\
\hline Total & 62.118 & 33 & & & \\
\hline \multicolumn{6}{|c|}{ DEAL WITH PLAGIARISM } \\
\hline Between Groups & 5.949 & 3 & 1.983 & 1.237 & .314 \\
\hline Within Groups & 48.081 & 30 & & & \\
\hline Total & 54.03 & 33 & & & \\
\hline \multicolumn{6}{|c|}{ USE PROTECTED MATERIALS } \\
\hline Between Groups & 3.804 & 3 & .985 & .522 & .598 \\
\hline Within Groups & 56.667 & 30 & 1.889 & & \\
\hline Total & 60.471 & 33 & & & \\
\hline \multicolumn{6}{|c|}{ USE DATA WITHOUT CONSENT } \\
\hline Between Groups & 6.189 & 3 & 2.063 & 1.155 & .343 \\
\hline Within Groups & 55.576 & 30 & 1.786 & & \\
\hline Total & 61.765 & 33 & & & \\
\hline
\end{tabular}


Table 3. One-way ANOVA for ethical challenges among different academic degrees

\begin{tabular}{|c|c|c|c|c|c|}
\hline Source & Sum of Squares & $d f$ & Mean Square & $F$ & $P$ \\
\hline \multicolumn{6}{|c|}{ PROTECT PRIVACY } \\
\hline Between Groups & 17.137 & 2 & 8.569 & 3.266 & .52 \\
\hline Within Groups & 81.333 & 31 & 2.624 & & \\
\hline Total & 98.471 & 33 & & & \\
\hline \multicolumn{6}{|c|}{ PROVIDE EQUAL ACCESS } \\
\hline Between Groups & 6.049 & 2 & 3.025 & 1.112 & .342 \\
\hline Within Groups & 84.333 & 31 & 2.720 & & \\
\hline Total & 90.382 & 33 & & & \\
\hline \multicolumn{6}{|c|}{ PROVIDE LD EQUAL ACCESS } \\
\hline Between Groups & 1.144 & 2 & .572 & .331 & .721 \\
\hline Within Groups & 51.826 & 30 & 1.728 & & \\
\hline Total & 52.970 & 32 & & & \\
\hline \multicolumn{6}{|c|}{ CONSIDER DIVERSITY } \\
\hline Between Groups & 3.284 & 2 & 1.642 & 1.075 & .354 \\
\hline Within Groups & 47.333 & 31 & 1.527 & & \\
\hline Total & 50.618 & 33 & & & \\
\hline \multicolumn{6}{|c|}{ PROTECT CONFIDENTIAL INFO } \\
\hline Between Groups & 19.049 & 2 & 9.525 & 5.019 & .013 \\
\hline Within Groups & 58.833 & 31 & 1.898 & & \\
\hline Total & 77.882 & 33 & & & \\
\hline \multicolumn{6}{|c|}{ DISTRIBUTE TASKS EQUALLY } \\
\hline Between Groups & 6.733 & 2 & 3.366 & 1.732 & .194 \\
\hline Within Groups & 66.708 & 31 & 2.152 & & \\
\hline Total & 73.441 & 33 & & & \\
\hline \multicolumn{6}{|c|}{ ENCOURAGE INDEPENDENCY } \\
\hline Between Groups & 6.733 & 2 & .263 & 1.564 & .225 \\
\hline Within Groups & 66.708 & 31 & 2.152 & & \\
\hline Total & 73.441 & 33 & & & \\
\hline \multicolumn{6}{|c|}{ AVOID POWER RELATIONS } \\
\hline Between Groups & .527 & 2 & .263 & .102 & .903 \\
\hline Within Groups & 80.208 & 31 & 2.587 & & \\
\hline Total & 80.735 & 33 & & & \\
\hline \multicolumn{6}{|c|}{ SURVEILLANCE OF INTERACTION } \\
\hline Between Groups & .284 & 2 & .142 & .071 & .931 \\
\hline Within Groups & 61.833 & 31 & 1.995 & & \\
\hline Total & 62.118 & 33 & & & \\
\hline \multicolumn{6}{|c|}{ DEAL WITH PLAGIARISM } \\
\hline Between Groups & 8.654 & 2 & 4.327 & 2.956 & .67 \\
\hline Within Groups & 45.375 & 31 & 1.464 & & \\
\hline Total & 54.029 & 33 & & & \\
\hline \multicolumn{6}{|c|}{ USE PROTECTED MATERIALS } \\
\hline Between Groups & 1.971 & 2 & .985 & .522 & .598 \\
\hline Within Groups & 58.500 & 31 & 1.887 & & \\
\hline Total & 60.471 & 33 & & & \\
\hline \multicolumn{6}{|c|}{ USE DATA WITHOUT CONSENT } \\
\hline Between Groups & 4.556 & 2 & 2.278 & 1.279 & .293 \\
\hline Within Groups & 55.208 & 31 & 1.781 & & \\
\hline Total & 59.765 & 33 & & & \\
\hline
\end{tabular}

\section{Copyrights}

Copyright for this article is retained by the author, with first publication rights granted to the journal.

This is an open-access article distributed under the terms and conditions of the Creative Commons Attribution license (http://creativecommons.org/licenses/by/4.0/). 